\title{
Suppression of Ischemic Edema in Mice by Manganese- Hyaluronate Conjugate
}

\author{
Katsukiyo Sakurai ${ }^{1,2}$, Mariko Andoh ${ }^{1}$, Motoyuki Yamada ${ }^{1}$, Yoh Kodera ${ }^{1}$, Hiroyuki Nishimura ${ }^{1}$, Misao Hiroto ${ }^{1}$, \\ Ayako Matsushima ${ }^{1}$, Masaaki Aoyama ${ }^{3}$, Hisao Yamamoto ${ }^{2}$ and Yuji Inada, ${ }^{1, *}$ \\ 'Toin Human Science and Technology Center, Department of Materials Science and Technology, \\ Toin University of Yokohama, Aoba-ku, Yokohama 225, Japan \\ ${ }^{2}$ The Tokyo Research Institute, Seikagaku Corporation, Higashiyamato, Tokyo 207, Japan \\ ${ }^{3}$ Institute for Life Support Technology, Yamagata Technopolis Foundation, Numagi, Yamagata 990, Japan
}

Received November 5, 1996 Accepted March 18, 1997

\begin{abstract}
Manganese-hyaluronate conjugate (Mn-HA) was synthesized from a diethylenetriaminepentaacetic acid derivative of hyaluronic acid and manganese ion. The conjugate markedly scavenged superoxide anion in vitro and exhibited much higher anti-inflammatory activity than superoxide dismutase in suppressing paw edema in mice when intravenously injected $30 \mathrm{~min}$ before the initiation of ischemia.
\end{abstract}

Keywords: Manganese-hyaluronate conjugate, Ischemic edema, Reactive oxygen species

Reactive oxygen species including superoxide anion $\left(\mathrm{O}_{2}{ }^{-}\right)$, hydroxyl radical $(\mathrm{OH} \cdot)$ and hydrogen peroxide $\left(\mathrm{H}_{2} \mathrm{O}_{2}\right)$ have been implicated as mediators of a wide variety of diseases such as radiation injury, hyperoxemia and inflammation, especially arthritis (1). In the case of ischemia-reperfusion, these oxygen intermediates are suggested to be generated by xanthine oxidase in endothelial cells as well as by NADPH oxidase and myeloperoxidase in accumulated phagocytes, and they play a major role in the reperfusion injury of tissues (2).

To remove these harmful oxygen species, various antioxidants and radical scavengers have been widely investigated. Superoxide dismutase (SOD), a unique metal enzyme containing copper and zinc $(\mathrm{Cu} / \mathrm{Zn})$ or manganese (Mn) at the catalytic site, has an activity of scavenging superoxide anion by dismutation into oxygen and hydrogen peroxide. Because of this ability, SOD has been experimentally or clinically applied for the treatment of inflammatory diseases $(3,4)$. In addition, various copper complexes synthesized as SOD model compounds show the superoxide anion-scavenging activity (5). However, these compounds as well as $\mathrm{Cu} / \mathrm{Zn}$-SOD could have a very short half-time in blood circulation and may potentiately generate extremely reactive hydroxyl radical from hydrogen peroxide by a Haber-Weiss reaction (6). Although Mn-SOD does not form the harmful

\footnotetext{
* To whom correspondence should be addressed.
}

byproduct, mammalian Mn-SOD may be less stable than $\mathrm{Cu} / \mathrm{Zn}-\mathrm{SOD}$ and the bacterial one may cause severe immune responses.

To overcome these disadvantages, we prepared a $\mathrm{Mn}$ complex coupled with hyaluronic acid (HA), a biodegradable and non-immunogenic biopolymer of typical glycosaminoglycan with a repeating disaccharide structure. HA is susceptible to degradation by reactive oxygen species and may protect tissues from oxidative damage in patients with inflammatory diseases (7). The present study deals with the oxygen radical-scavenging activity of manganese-hyaluronate conjugate (Mn-HA) and its suppressive effect on ischemic edema.

Manganese-hyaluronate conjugate (Mn-HA) was prepared as shown in Fig. 1. HA with molecular weight of $1,000,000$ from rooster comb (Seikagaku Co., Tokyo) has approximately 2,500 repeating dimeric units of $N$-acetylD-glucosamine and D-glucuronic acid. The carboxyl groups of HA were coupled with ethylenediamine dihydrochloride by 1-ethyl-3-(3-dimethylaminopropyl)carbodiimide hydrochloride (EDC; Dojindo, Kumamoto). The amine derivative of $\mathrm{HA}\left(\mathrm{NH}_{2}-\mathrm{HA}\right)$ was then coupled with diethylenetriamine- $N, N, N^{\prime}, N^{\prime \prime}, N^{\prime \prime}$-pentaacetic dianhydride (DTPA anhydride, Dojindo) to prepare the DTPA derivative of HA (DTPA-HA). Mn-HA was obtained by adding manganese(II) chloride to the DTPAHA solution. In each step, excess reagents were removed by dialysis against $0.15 \mathrm{M} \mathrm{NaCl}$. The amount of $\mathrm{HA}$ was 
calculated on the basis of uronic acid determined by the carbazole-sulfate method (8).

The molar ratios of ethylenediamine and DTPA coupled to the carboxyl groups of HA were determined to be $6.4 \mathrm{~mol} \%$ and $6.0 \mathrm{~mol} \%$, respectively, by the ninhydrin method. The content of $\mathrm{Mn}$ in the Mn-HA was $5.5 \mathrm{~mol} \%$ as determined by an inductively coupled plasma (ICP) atomic emission spectrometer (SPS7000A; Seiko Instruments, Inc., Chiba), and the value closely agreed with that of DTPA content. Further dialysis of the conjugate against $0.15 \mathrm{M} \mathrm{NaCl}$ could not decrease its $\mathrm{Mn}$ content. On the other hand, $\mathrm{Mn}$ ion was released from the mixture of $\mathrm{MnCl}_{2}$ and $\mathrm{HA}$ during an equilibrium dialysis against $0.15 \mathrm{M} \mathrm{NaCl}$. Therefore, $\mathrm{Mn}$ in the conjugate forms a

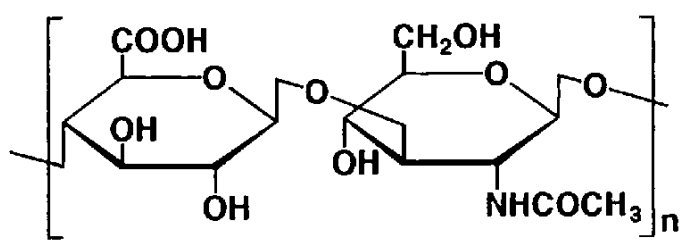

Hyaluronic acid (HA)

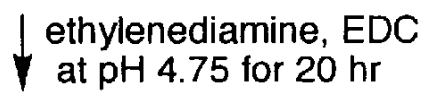

$\mathrm{NH}_{2}-\mathrm{HA}$

$\downarrow$ DTPA anhydride at $p H 7.0$ for $1 \mathrm{hr}$

DTPA-HA

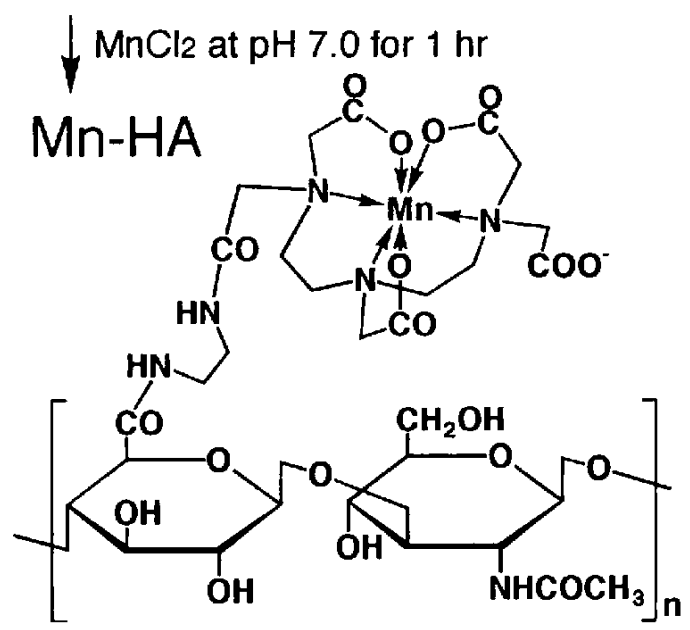

Fig. 1. Preparation of manganese-hyaluronate conjugate (MnHA). To HA (1 g, $2.5 \mathrm{mmol}$ as COOH group) dissolved in $200 \mathrm{ml}$ of $\mathrm{H}_{2} \mathrm{O}$ was added ethylenediamine $(5 \mathrm{mmol})$ and EDC (10 mmol). To $\mathrm{NH}_{2}$-HA was then added DTPA anhydride $(1.5 \mathrm{mmol})$ in $200 \mathrm{ml}$ of $0.1 \mathrm{M}$ HEPES-HCl containing $0.15 \mathrm{M} \mathrm{NaCl}(\mathrm{pH} 7.0)$, followed by the addition of $\mathrm{MnCl}_{2}(1.5 \mathrm{mmol})$. In each step, sufficient dialysis against $0.15 \mathrm{M} \mathrm{NaCl}$ was carried out. stable chelate complex with DTPA, which may be due to the high complex stability constant between DTPA and $\mathrm{Mn}^{2+}(\log \mathrm{K}=16)(9)$.

To estimate the stability of the conjugate in blood circulation, $1 \mathrm{mg}$ of Mn-HA dissolved in $0.4 \mathrm{ml}$ of saline was injected into a tail vein of male ddY mice (10-weeksold; Kiwa Laboratory Animals, Tokyo). At given times, the Mn concentrations in serum were determined by the ICP method (data not shown). Forty minutes after the injection, approximately $10 \%$ of the initial concentration of $\mathrm{Mn}$ remained in the serum. On the contrary, the concentration fell to $10 \%$ within 2 min after the injection of free Mn ion or a mixture of $\mathrm{Mn}$ and HA.

Figure 2a shows the ESR spectra of superoxide anion in the presence of 5,5-dimethyl-1-pyrroline $\mathrm{N}$-oxide (DMPO, Dojindo). The intensity of the control signals was clearly diminished by adding Mn-HA in a dose-dependent manner, but was not by HA only. The signals were also diminished by adding $\mathbf{M n C l}_{2}$ or $\mathbf{M n}$-SOD from Bacillus stearothermophilus (Seikagaku Co.). The 50\% inhibitory concentration $\left(\mathrm{IC}_{50}\right)$ of Mn-HA determined by the cytochrome $c$ method (10) was $6 \times 10{ }^{6} \mathrm{M}$ based on the Mn concentration. The suppression of cytochrome $c$ reduction could not be observed by adding HA up to 1.7 $\mathrm{mg} / \mathrm{ml}$. The values of $\mathrm{MnCl}_{2}$ and $\mathrm{Mn}$-SOD were $1 \times 10^{-6}$ $\mathrm{M}$ and $2 \times 10^{-8} \mathrm{M}$, respectively. The superoxide scavenging activity of Mn-HA is similar to that ot free Mn ion. In the case of hydroxyl radical, the intensity of the ESR signals (Fig. 2b) was partially diminished with Mn-HA, while a clear decrease in the intensity could not be observed with $\mathrm{HA}, \mathrm{MnCl}_{2}$ or $\mathrm{Mn}$-SOD.

The anti-inflammatory activity of Mn-HA was determined using an experimental ischemia model (11). MnHA was intravenously injected to male ddY mice (8weeks-old). After $30 \mathrm{~min}$, a suture was tied around the right hind leg of each mouse. One end of the suture was fixed while the other end was tensed with a weight of 300 g. After $40 \mathrm{~min}$ of ischemia, the suture was removed and blood flow was reperfused for $20 \mathrm{~min}$. The thickness of the instep of the ischemic foot was measured with slide calipers, which was normalized as a percentage of increase by comparing it with that measured before the ischemia.

As a result of ischemic paw edema, the thickness of the mouse paw was increased by $30.8 \pm 3.6 \%$ in comparison with that before ischemia (Fig. 3). The administration of Mn-HA markedly suppressed the edema; the increase in the foot-pad thickness was only $10.7 \pm 5.2 \%$. On the contrary, the thickness was increased by $21.2 \pm 4.8 \%$, $28.3 \pm 2.8 \%$ and $30.1 \pm 4.2 \%$ when mice were treated with $\mathrm{HA}$, free $\mathrm{Mn}$ ion, and a mixture of Mn and HA, respectively, in the same amount as Mn-HA on a molar basis. Furthermore, the foot-pad thickness was also increased 
(a) superoxide anion $\left(\mathrm{O}_{2}^{-}\right)$

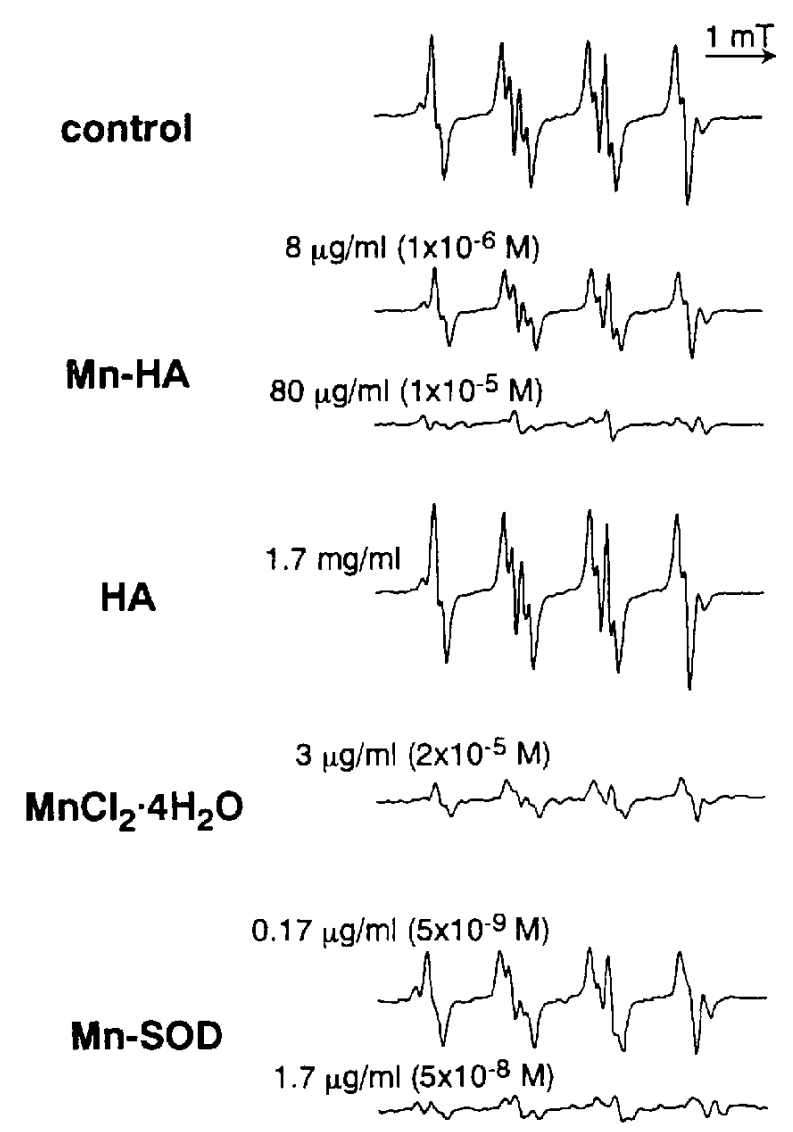

\section{(b) hydroxyl radical $(\mathrm{OH} \cdot)$}

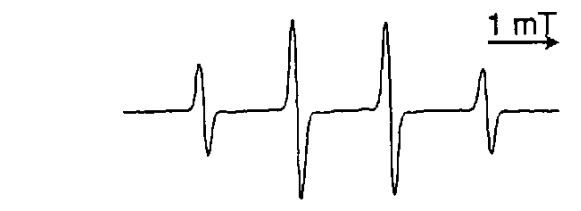

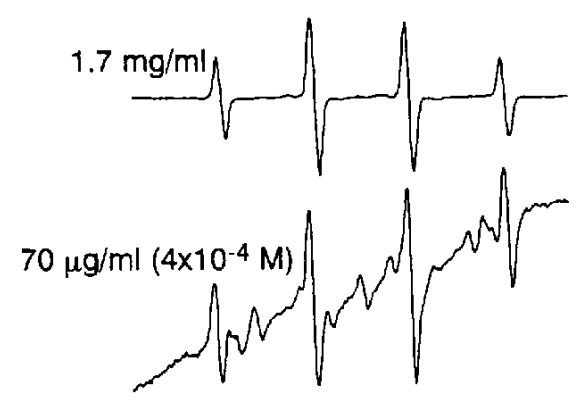

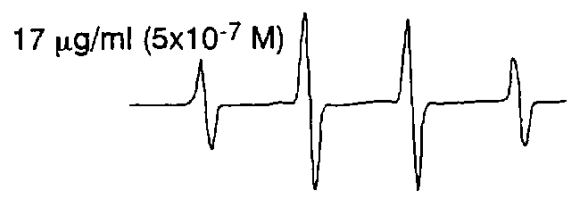

Fig. 2. ESR spectra of superoxide anion (a) and hydroxyl radical (b) in the presence of Mn-HA and DMPO. The Mn concentration of each sample is indicated in parentheses. Superoxide anion was generated by the hypoxanthine-xanthine oxidase system (10) containing $30 \mathrm{mM}$ DMPO, and hydroxyl radical was generated from ferrous sulfate $(0.1 \mathrm{mM})$, hydrogen peroxide (1.5 mM) and DMPO (30 mM) in 0.1 M phosphate buffer, pH 7.5. ESR was carried out with a Jeol FR-80 spectrometer (Tokyo) under the following conditions: modulation frequency (50 or $200 \mathrm{kHz})$, modulation amplitude $(0.079 \mathrm{mT})$, scanning field $(336.1 \pm 5 \mathrm{mT})$, receiver gain $(5 \times 100)$, response time $(0.1 \mathrm{sec})$, sweep time $(1 \mathrm{~min})$ and microwave power $(4 \mathrm{~mW})$ at room temperature. The xanthine oxidase activity monitored by urate formation (15) was not inhibited by the conjugate.

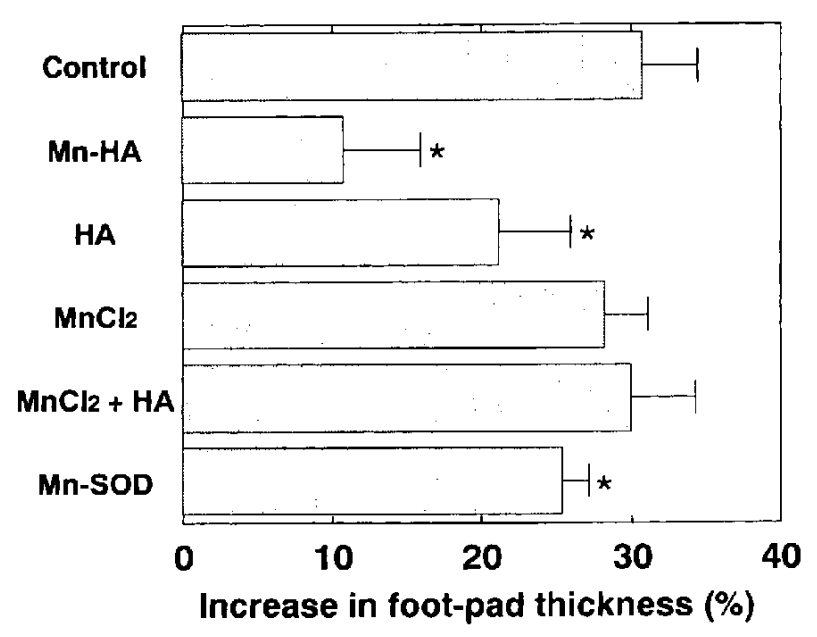

$(25.4 \pm 1.8 \%)$ by a injection of Mn-SOD at the same SOD activity as Mn-HA.

Ischemia-reperfusion paw edema, a model of superoxide anion-related inflammatory diseases, is reported to be suppressed by SOD injection just before the ischemia (11). The suppression of edema by Mn-HA suggested its effective scavenging of harmful radicals in vivo as demonstrated in our in vitro experiments. As the suppressive effect on the edema was only observed with Mn-

Fig. 3. Suppression of ischemia-reperfusion paw edema by MnHA. Male ddY mice were treated with saline $(\mathrm{n}=7)$ or a sample: $\mathrm{Mn}-\mathrm{HA}(50 \mu \mathrm{g}, \mathrm{n}=7)$, HA $(50 \mu \mathrm{g}, \mathrm{n}=5), \mathrm{MnCl}_{2} \cdot 4 \mathrm{H}_{2} \mathrm{O}(1.6 \mu \mathrm{g}$, $\mathrm{n}=5$ ), a mixture of $\mathrm{HA}$ and $\mathrm{MnCl}_{2} \cdot 4 \mathrm{H}_{2} \mathrm{O}$ (50 and $1.6 \mu \mathrm{g}$, respectively, $n=4)$, and $M n-S O D(1 U, n=6)$. Each bar indicates a mean \pm S.D. ${ }^{*} \mathrm{P}<0.01$ vs control group by Student's $t$-test. 
HA but not with a mixture of Mn and HA or Mn-SOD, the advantage may be mainly due to the longer clearance time of Mn-HA in blood circulation. Although the radical scavenging activity of HA was hardly detected in vitro, ischemic paw edema was slightly suppressed by HA only. As is expected, HA was endowed with superoxide anion scavenging activity by the conjugation with $\mathrm{Mn}$. The suppression of paw edema by Mn-HA was significantly effective in comparison with that by HA only. Moreover, Mn-HA seems to have a hydroxyl radical scavenging activity.

HA, bound to proteoglycan in amorphous intercellular matrix, is reported to act as an anti-inflammatory molecule (12) by inhibiting the adherence of immune complexes to neutrophils (13) and by protecting tissues from the attachment of inflammatory mediators (14) in inflamed joints. Mn-HA with an enhanced radical scavenging activity may exhibit more suppressive activity by a local injection to the inflammatory regions.

\section{REFERENCES}

1 Greenwald RA: Superoxide dismutase and catalase as therapeutic agents for human diseases. Free Rad Biol Med 8, $201-209$ (1990)

2 McCord JM: Oxygen-drived free radicals in postischemic tissue injury. N Engl J Med 312, 159-163 (1985)

3 Ohno H, Takayanagi N, Murase J and Iwata H: Anti-inflammatory effect of superoxide dismutase on carrageenin-induced arthritis in rabbits. Folia Pharmacol Jpn 82, 375-381 (1983) (Abstr in English)

4 Manson PN, Bulkley GB and Hoopes JE: Effects of superox- ide dismutase and allopurinol on the survival of acute island skin flaps. Ann Surg 201, 357-359 (1985)

5 Ueda J, Sudo A, Mori A and Ozawa T: Generation of hydroxyl radicals during dismutation of superoxide by SOD model compounds. Arch Biochem Biophys 315, 185 - 189 (1994)

6 Sato $\mathrm{K}$, Akaike T, Kohno M, Ando $\mathrm{M}$ and Maeda $\mathrm{H}$ : Hydroxyl radical production by $\mathrm{H}_{2} \mathrm{O}_{2}$ plus $\mathrm{Cu}, \mathrm{Zn}$-superoxide dismutase reflects the activity of free copper released from the oxidatively damaged enzyme. J Biol Chem 267, 25371-25377 (1992)

7 Sato $\mathbf{H}$, Takahashi $\mathbf{T}$, Ide H, Fukushima T, Tabata M, Sekine F, Kobayashi K, Negishi $M$ and Niwa $Y$ : Antioxidant activity of synovial fluid, hyaluronic acid, and two subcomponents of hyaluronic acid. Arthritis Rheum 31, 63-71 (1988)

8 Bitter T and Muir HM: A modified uronic acid carbazole reaction. Anal Biochem 4, 330- 334 (1962)

9 Sillen LG and Martell AE: In Stability Constants of Metal IonComplexes, pp 694-695, Burlington House, London (1964)

10 McCord JM and Fridovich I: Superoxide dismutase, an enzymic function for erythrocuprein (hemocuprein). J Biol Chem 244, $6049-6055$ (1969)

11 Oyanagui Y, Sato S and Okajima T: Suppressions of ischemic paw oedema in mice, rats and guinea pigs by superoxide dismutases from different sources. Free Rad Res Commun 4, $385-396$ (1988)

12 Yehia SR and Duncan H: Synovial fluid analysis. Clin Orthop Related Res 107, 11-24 (1975)

13 Brandt K: Modification of chemotaxis by synovial fluid hyaluronate. Arthritis Rheum 13, 308-309 (1970)

14 Miyazaki K, Goto S, Okawara $\mathrm{H}$ and Yamaguchi T: Analgesic and anti-inflammatory effects of sodium hyaluronate (SPH). Oyo Yakuri 28, 1123-1135 (1984)

15 Heinz F and Reckel S: Xanthine oxidase. In Methods of Enzymatic Analysis, Vol 3, pp 210-216, Verlag Chemie, Weinheim (1983) 